DOI: 10.20472/IAC.2019.045.008

SONIA DALMIA

Grand Valley State University, United States

\title{
A COMPARISON OF MARITAL MATCHING IN FIRST AND SECOND MARRIAGES
}

\begin{abstract}
:
Data from the U.S. Census Bureau reveal that in 2013, four-in-ten new marriages included at least one partner who had been married before, and two-in-ten new marriages were between people who had both previously stepped down the aisle. Although, the incidence of remarriage has increased, equilibrium sorting in second marriages has received far less attention in the literature compared to matching patterns in first marriages. Understanding the sorting process is useful since the quality of marital matches influences many economic and social outcomes such as marital stability, fertility, child welfare, income distribution within and across families and labor supply decisions. Furthermore, it is likely that these outcomes may change over time as the maturing process following the first marriage may alter the selection criteria and have a disparate effect on assortative mating patterns in subsequent marriages.

Although, a considerable number of studies have examined the factors affecting the time and propensity to remarry, studies on the marital matching process in remarriages are few, not current, have small sample sizes and lack advanced empirical techniques. This paper constructs an empirical model of spouse selection based on Becker's efficient marriage market hypothesis, in which optimal assignments of marriage partners are derived from maximizing the household output function. By specifying a marital production function and introducing the influence of multiple individual characteristics simultaneously in the matching technology, this paper creates a matching algorithm and uses the estimated parameters to not only assess patterns of assortative mating, but also to isolate factors that drive matching behaviors in first and second marriages.

Using a nationally representative multi-cohort longitudinal data of newly admitted legal immigrants and their children to the United States, this paper finds support for Becker's predictions of positive assortative mating on all observable traits. Results reveal that while the outcome of the process of mate selection is driven almost entirely by the economic assets of the male, his income, in the first marriage, the noneconomic assets of the male, his age, play a bigger role in the second marriage. Although the emphasis on female age increases with the second marriage, female age, a proxy, for reproductive potential, remains the main driver of the selection process. Overall, results indicate that the selection criteria changes more for women than for men with higher order of marriage. Finally, the equilibrium sorting indicates that the incidence of likes marrying likes increases significantly with the second marriage.
\end{abstract}

\section{Keywords:}

Marital assignments, division of labor, market efficiency

JEL Classification: C61, C78, D13 